REVIEW PAPER

\title{
FUNCTIONAL CHARACTERISTICS, DRY HEATING AND IRRADIATION TREATMENT OF STARCH- A SHORT REVIEW
}

\author{
ARIJIT DUTTA GUPTA ${ }^{1}$, RUPANJALI SINGH ${ }^{1}$, VIVEK KUMAR JAISWAL ${ }^{1}$, K.P. RAWAT ${ }^{2}$, \\ HARINDER SINGH $^{1 *}$, VIVEK BHADAURIA ${ }^{3}$, RAKESH PUNIA ${ }^{1}$ \\ ${ }^{1}$ Department of Chemical Engineering, Motilal Nehru National Institute of Technology Allahabad, Prayagraj, \\ India-211004. \\ ${ }^{2}$ BRNS, 1st floor, Central Complex, Bhabha Atomic Research Centre, Trombay, Mumbai, India-400085. \\ ${ }^{3}$ Department of Chemistry, Ewing Christian College, Prayagraj, India-211003 \\ *corresponding author: harinderpdfb@gmail.com \\ Received on 9 January 2020 \\ Revised on 18 May 2020
}

\begin{abstract}
Physical modification of starches using dry heating, gamma and electron beam irradiation are considered greener and more cost effective than using crosslinking chemicals for starch modification. Chemical modification of starches generates lot of downstream waste. Alternatively, dry heating of starches can also be utilized to influence hydrolysis as well as crosslinking of chains and requires no catalyst. Gamma and electron beam irradiation although used largely for preservation of foods can introduce carboxyl groups into starch molecules as well as degrade starch chains. Gamma and electron beam irradiation can hydrolyze as well as cross link starches which can have various applications in food and process industries. Irradiation and dry heating are promising techniques and can be used in conjunction with other modifications type for making specialty and resistant starches. To the best of our knowledge dry heating of starches has not been reviewed. Need was also felt to critically review irradiation techniques since there are many ongoing debates on its implications.
\end{abstract}

Keywords: food processing, food irradiation, starch, gamma rays, dry heating

\section{Introduction}

Starch, cellulose and chitosan are three most abundant and renewable biopolymers in the world. These three biopolymers are of high economic and social importance and are getting increased attention due to various end uses and potential alternatives to plastics. Starch is the major source of energy in human diet. It is majorly derived from pulses, tubers and cereals in human diet. According to FAO (Food and Agriculture Organization of the United Nations, 2010) maize is the cereal produced in the world in highest quantities followed by wheat rice, barley

https://doi.org/10.35219/foodtechnology.2020.1.13 
and sorghum. China, India, Russia and USA are the largest producers of wheat, sorghum, maize and rice. Pulses are very important sources of proteins and energy for poor countries. India, Pakistan, China, Myanmar, USA, Canada are major producers of major pulses like field peas, chickpeas, cowpeas, green gram, black gram, lentils, pigeon peas and oil seeds like groundnuts and soybeans however, soybeans and groundnuts are not sources of starch. Tubers are good sources of sugars, starches and minerals. Worldwide production of cereals was 2600 million tons in the year 2017- 2018 whereas pulses and tuber (potatoes and sweet potatoes) production stood at 87.40 million tones and 401 million tons in the same period (Surendra Babu et al., 2015).

Starch is a biopolymer of amylose and amylopectin. Native and modified forms of starches are used in paper, textile, food, cosmetics, polymer and pharmaceutical industries. In the food industry, starch is used as thickener, emulsion stabilizer and for gelling, film forming, delivery of nutrient and retention of moisture (Wurzburg, 1986).

Starch is extracted majorly from cereals (corn, wheat) and potato for various uses in food and other industries. Yet it may be noted that due to increased usage of corn, wheat and potato in various food products there is always look out for either new sources or for modification of starch. Some of the new sources of starch may be barley, sorghum and pulses. Also, starch in its unmodified form suffers from various drawbacks and is modified physically, chemically and enzymatically to achieve target properties. Physical modification of starch includes use of thermal energy, shear energy, radiation, ultrasonication etc for altering physicochemical and functional properties of starch. Chemical modification of starches is performed by breakage/ formation of new bonds and adding functional groups, cross links etc. Chemicals used for modification of starch are hydrochloric acid, acetic anhydride, phosphoric acid, sodium hypochlorite in combination or alone. Physical treatment include irradiation, heat moisture treatment, microwave etc. Enzymatic treatment of starches use various enzymes like $\alpha, \beta$ amylase, pullanase. Cellulose and chitosan are used as antioxidant agent, fiber in food products, however their use as bulking, texturing or stabilizing agent in food products as compared to starch is almost negligible.

Starch modification involving crosslinking chemicals are not green methods. Also there are costs associated with purchase and recovery of these chemicals and with waste water treatment in the industries using chemical cross linking of starches. The replacement of chemical cross linking and hydrolysis is one of the hot topics of interest. This would lead to benefits of increased green foot print as well as cost savings. Emphasis is these days on irradiating starches or on dry heating so as to achieve same properties as chemical modified starches. This review critically discusses the work done on these modifications in the past 20 years along with introduction on functional characteristics of starch for easy relation by reader with changes occurring in starches on dry heating and irradiation. 


\section{Starch structure and morphology}

Usually starches consist of $20 \%$ to $30 \%$ amylose, although pulses and Hylon corn starches may show amylose content as high as 30-70\% (Hoover et al., 2010; Singh et al., 2017). Amylose content in starch, granule size and chain lengths of amylose and amylopectin may depend on biological origin and growth conditions of crop (Smith, 2001).

Amylose is a linear polymer with a 1-4 glycosidic linkages between glucose monomers and its degree of polymerization (DP) varies between $5 \times 10^{2}-5 \times 10^{3}$ and molecular weight between $10^{5}-10^{6}$. Amylopectin is a branched polymer having $\alpha$ 1-4 and 1-6 glycosidic linkages. Its DP varies between $10^{5}-10^{6}$ and molecular weight between $10^{7}$ and $10^{9}$ (Tester et al., 2004). Amylose and amylopectin constitute major fraction (99\%) of all starches except for waxy starch in which amylose content ranges between 0-5\% (Tester et al., 2004).

Morphology of starch granules can affect physicochemical and rheological properties of starch and starch based food products significantly. Morphology of starch granules depends on botanical source, chloroplast chemistry and may be affected by grain development stage and milling practices (Table 1). Starch granules in wheat and barley usually have bimodal distribution of sizes whereas starch from sorghum, corn and pulses show unimodal distribution (Singh et al., 2017; Katyal et al., 2019). The pulse starch granules usually exhibit oval, irregular and round shapes. The starch granules from various pulses usually do not exhibit surface roughness or indentation (Chung et al., 2008) whereas starch granules of sorghum and corn have been reported to exhibit pores and channels (Singh et al., 2010). Potato starch morphology have been related to amylose content (Singh and Kaur, 2004).

\section{Crystallinity of starch}

Starch is semi crystalline with relative crystallinity varying between $20-40 \%$ (Babu et al., 2015; Singh et al., 2017). Amorphous portions of starch are hypothesized to be made of amylose and amylopectin in disordered form (Wang et al., 2015). The crystalline portion results due to packing of amylopectin chains (Tester et al., 2004). The internal branches of amylopectin have been reported to be located in the amorphous lamellae of the granules, whereas the external chains have been hypothesized to form the double helices and contribute to crystalline lamellae of granule (Vamadevan and Bertoft, 2015). Crystallinity of starches can be affected by crystal size, quantity and quality, packing and interaction of chains, chain lengths and double helices and any modification performed (Hoover et al., 2010).

\section{Swelling power and solubility}

Intergranular and intragranular swelling and solubilization of starch granules indicates the water binding ability of granules and leaching of soluble materials in water when starch suspension is heated at temperatures near to or higher than gelatinization temperature. Swelling behavior of starches have been observed to depend on proportion of A type polymorph (Chung et al., 2008). Swelling behavior of starches in general can be affected by amylose content, chain profiles, 
interactions between starch chains and relative crystallinity (Miao et al., 2014; Tester and Morrison 1994).

Table 1. Morphology and X-ray diffraction (XRD) patterns of starches from various sources.

\begin{tabular}{|c|c|c|c|c|c|}
\hline $\begin{array}{l}\text { Starch } \\
\text { Source }\end{array}$ & $\begin{array}{l}\text { Scientific } \\
\text { Name }\end{array}$ & Shape & Size & $\begin{array}{l}\text { XRD } \\
\text { Type }\end{array}$ & Authors \\
\hline Barley & $\begin{array}{l}\text { Hordeum } \\
\text { vulgare }\end{array}$ & Oval & -- & A & $\begin{array}{l}\text { Darlington } \\
\text { et al., } 2000\end{array}$ \\
\hline $\begin{array}{l}\text { Chick } \\
\text { pea }\end{array}$ & Cicer arietinum & Oval, spherical & Unimodal & $\mathrm{C}$ & $\begin{array}{l}\text { Huang et al., } \\
2007\end{array}$ \\
\hline Corn & Zea mays & $\begin{array}{l}\text { Round, elongated } \\
\text { and irregular }\end{array}$ & --- & A & Fu et al., 2013 \\
\hline Lentil & Lens culinaris & $\begin{array}{l}\text { Oval, round, } \\
\text { elliptical }\end{array}$ & Unimodal & $\mathrm{C}$ & $\begin{array}{l}\text { Chung et al., } \\
2008\end{array}$ \\
\hline Potato & $\begin{array}{l}\text { Solanum } \\
\text { tuberosum }\end{array}$ & $\begin{array}{l}\text { Oval and } \\
\text { spherical }\end{array}$ & Bimodal & B & $\begin{array}{l}\text { Hu et al., } \\
2009\end{array}$ \\
\hline Rice & Oryza sativa & $\begin{array}{l}\text { Polyhedral and } \\
\text { irregular }\end{array}$ & --- & A & $\begin{array}{l}\text { Wu et al., } \\
2010\end{array}$ \\
\hline $\begin{array}{l}\text { Sweet } \\
\text { Potato }\end{array}$ & Ipomoea batatas & Polygonal & ---- & $\mathrm{C}$ & $\begin{array}{l}\text { Surendra Babu } \\
\text { et al., } 2015\end{array}$ \\
\hline Wheat & $\begin{array}{l}\text { Triticum } \\
\text { aestivum }\end{array}$ & $\begin{array}{l}\text { Spherical, round, } \\
\text { lenticular }\end{array}$ & $\begin{array}{l}\text { Trimodal and } \\
\text { named as } A, B \\
\text { and } C \text { type } \\
\text { granules with } \\
\text { size } A>B>C\end{array}$ & A & $\begin{array}{l}\text { Katyal et al., } \\
2019\end{array}$ \\
\hline
\end{tabular}

\section{Gelatinization, retrogradation and pasting properties}

Starch gelatinization consists of swelling of starch granules in water and molecular disorganization leading to crystallinity loss (Noda et al., 2003). Hence, gelatinization can be described as the order to disorder change when starch is heated in excess water. Starch to water ratio used during gelatinization of starch is a significant parameter which affects the stability of crystallites. Water or solvent used during gelatinization has plasticizing effects and its absorption in amorphous domains causes destabilization (Fallis, 2013).

During storage of starch gel at low temperatures starch chains reorganizes slowly from amorphous state to ordered state, which depends on amylose chain length, storage temperature and period and branching extent of amylopectin (Bao et al., 2007). Water or solvent exudation from the gel during the storage is termed as syneresis (Waigh et al., 2000). Retrogradation can lead to bread going stale and reduction in shelf life of starch based foods due to increase in water activity.

Retrogradation phenomena is usually measured by DSC. Other methods of measurement include syneresis which is percentage of water released by starch gel during storage or by using Rapid Visco Analyzers or Rheometers which rely on changes in viscosity/storage modulus during heating and cooling cycle. 
Starch paste is composed of granule ghosts and leached amylose and amylopectin in water. When starch suspension is heated in water, the granule start swelling and eventually burst (Singh et al., 2012). This occurs due to heat energy and shearing of starch suspension. Pasting of starches is the development of viscosity upon applying heating-cooling cycle and shearing on starch suspensions. Heating of starch in water causes gelatinization, uptake of water by granules, melting of crystallites. The rupture of granules during heating leads to leaching of amylose and granular remnant solubilization. The leached amylose forms network with water. On cooling retrogradation of starch granules occurs which is realignment of amylose and amylopectin chains in the starch gel.

The temperature at which viscosity of starch water suspension occurs on heating is called pasting temperature (PT). Maximum viscosity of starch gel obtained during heating of starch in water is termed as peak viscosity (PV) (Newport, 1998). PV is in fact a measure of the maximum extent of free swelling of starch granules before the breakdown to release amylose (Singh et al., 2017; Singh and Kaur 2004). There are varying reports of relation of amylopectin chain architecture with peak viscosity of starches. No significant correlation between amylopectin branch chain structure and PV of starches was observed by Han and Hamaker (2001). However, Mua and Jackson (1997) observed higher PV for amylopectin than amylose. There is decrement in viscosity after peak viscosity point due to bursting of granules. After granules have swelled to maximum extent it is followed by breaking of granules and viscosity decreases. The minimum value of viscosity is termed hot paste viscosity (HPV). Breakdown (BD) viscosity has been stated to be a measure of thermal stability and shear resistance of granules before breaking (Singh et al., 2012). BD is obtained by difference between peak and hot paste viscosity. Final or cold paste viscosity (FV) is the equilibrium viscosity achieved during the cooling period and has been observed to be affected by starch type and shear rate. FV has been reported to be affected by the reassociation of leached amylose which forms continuous phase (Singh et al., 2007; Singh et al., 2010). Setback viscosity (SB) is an indication of short time retrogradation and is obtained by difference between FV and HPV (Newport, 1998). It has been reported to be caused by amylopectin recrystallization which occurs by interwining of outermost branches of amylopectin (Hoover et al., 2010). It is also affected by the re-linkages occurring between amylose chains (Srichuwong and Jane, 2007). Pasting properties may depend upon the genetic, environmental factors of growth of crops, granular strength and size and chain architecture of amylose and amylopectin (Noda et al., 2003). A typical pasting curve obtained for sorghum starch and its irradiated derivative is shown in Figure 1.

\section{Resistant starch}

According to Englyst et al. (2010), starch is classified into three main components depending on digestion and rate of glucose release: rapidly digestible starch (RDS); slowly digestible starch (SDS) and resistant starch (RS). RDS ingestion may determine a sudden surge in blood glucose level. Difference between SDS and RS lies in the fact that former is digested in the small intestine while the latter is 
absorbed only in the large intestine (Jenkins and Donald, 1995). Resistant starch presents resistance to breakdown by enzymes in small intestine. It is considered good for colon health being equivalent to dietary fiber and can improve metabolism of probiotic microorganisms. Its intake is also considered efficient against colon cancer (Singh et al., 2007). Slowly digestible starch has been associated with obesity prevention as it has stabilizing effect on glucose metabolism and satiety (Lehmann and Robin, 2007).

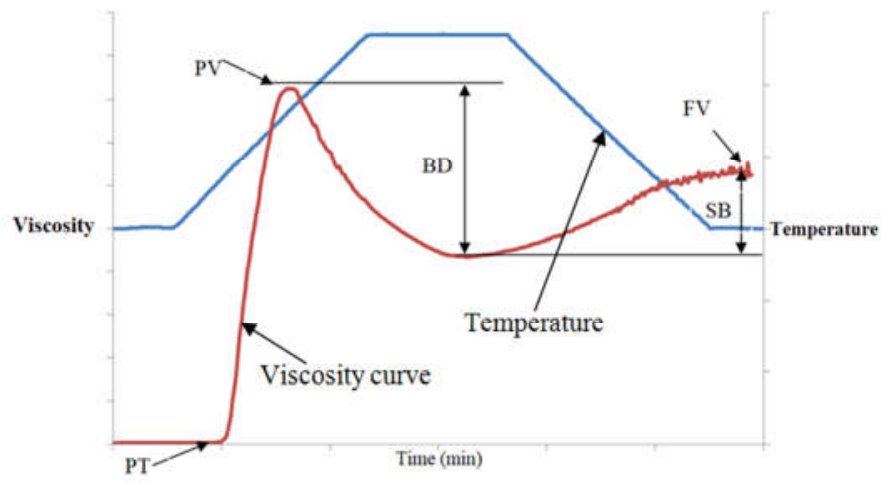

Figure 1. Typical starch pasting curve.

Resistant starch can be categorized into five classes: RS1- inaccessible to enzymes because of its entanglement in plant cell (e.g. whole grains), RS2- raw starch granules (e.g. banana starch or pulses starch), RS3- retrograded starch, RS4, chemically modified starch (e.g. cross linked starch) and RS5- single-helix of amylose -lipid complex (Arocas et al., 2009). The digestibility of starches isolated from pulses have been reported to be higher than potato and high amylose corn starches, but lower than the starches isolated from cereals (Chung et al., 2008; Parker and Ring 2001). Digestibility of starches can be affected by granule size, surface area, amylose content and relative crystallinity (Hoover et al., 2010).

\section{Dry heating}

Dry heating is one of the recent and safe physical treatments of starch. Although energy intensive, yet it does not lead to downstream wastes and is environmental friendly. Dry heating is similar to heat moisture treatment of starches, both consisting in heating starch at temperatures above gelatinization point for durations ranging from 15 minutes to several days. However, heat moisture treatment also includes addition of moisture (10-40\% w/w) to starch (Hoover et al., 2010; Singh et al., 2011). Annealing of starches is another physical modification involving higher moisture content addition $(60 \% \mathrm{w} / \mathrm{w})$ and heating at temperatures higher than gelatinization temperatures. Heat moisture treatment of pulse starches (lentil, pigeon and pea) has been reported to cause reduction in swelling power and increase in gelatinization temperature and hydrolytic action by alpha-amylase (Chung et al., 2008; Hoover et al., 2010). Both annealing and heat moisture 
treatment did not cause any breakage of the granules however, interactions between starch chains and perfection of starch crystals were observed to be enhanced (Singh et al., 2011). These treatments lead to rearrangement of starch chains and lesser interference of amylose in starch crystallites became evident in increase of gelatinization temperatures of starches (Hoover et al., 2010; Singh et al., 2011). Increase in resistant starch content and relative crystallinity and a decrease in swelling power of mung bean starch after the heat moisture treatment (15-35\% moisture $\mathrm{w} / \mathrm{w} 120^{\circ} \mathrm{C}$ ) was observed by Tian et al. (2011).

Dry heating of starches is an extensively used physical modifications of starches. Heating of dry starches (moisture content less than $10-15 \% \mathrm{w} / \mathrm{w}$ ) above $100{ }^{\circ} \mathrm{C}$ for durations higher than one hour was pioneered by Chiu et al. (1998). Campo-Deaño et al. (2009) isolated starch from steam heated pulses (black, red and lima beans) and observed more resistant starch content than shown by starch isolated from raw seeds. These authors also used the term 'dry heated starch' for the starch isolated from steam heated pulses. However, dry heating term in almost all studies has been used for heating of dry starch at high temperatures.

Dry heated starch and cross linked starches have similar thermal and $\mathrm{pH}$ stability characteristics (Morrison, 1988; Won et al., 2000). Granular structure has been reported to remain constant in almost all studies on dry heating. Dry-heating was carried out to modify the hydrophobicity of quinoa starch (Marefati et al., 2013). Changes in granular strength and pasting viscosities of rice starch after dry heating were found to be dependent on duration and temperature of dry heating treatment by Lele et al. (2018). Resistant starch content was also observed to increase on dry heating treatment by these authors.

Decrease in gelatinization temperature and enthalpy of gelatinization of proso millet starch was observed after dry heat treatment at $130^{\circ} \mathrm{C}$ for $2-4$ h by Sun et al . (2014). Gonzalez-Tomás et al. (2008) reported a reduction in crystallinity and gelatinization enthalpy of flour after dry heating treatment by fluidization at 150$200{ }^{\circ} \mathrm{C}$ and moisture contents of 12,16 and $20 \% \mathrm{w} / \mathrm{w}$ for 18 seconds. Interactions between starch chains and formation of hydrogen bonds were enhanced on dry heating as observed from IR spectra of native and dry heated proso millet starch (Sun et al., 2014). Addition of gums or amino acids under dry heating of starches has been also carried out for achieving target functional properties (Li et al., 2017). Combination of dry heating and chemical modification with ocetnyl succinic anhydride was used to modify waxy corn starch by Chung and Liu (2010). Dry heating increased degree of substitution of succinylation in waxy corn starch and the starch was also found to be good fat substitute in muffins. Dry heating of starch with lysine resulted into cross linking between lysine and starch leading to reduction in relative crystallinity and increase in peak viscosity of the treated starch (Kim et al., 2016). Similarly, Zuo et al. (2013) modified corn starch with maleic anhydride (4:1) under dry heating $\left(50-90{ }^{\circ} \mathrm{C}\right)$ for $1-4 \mathrm{~h}$ and demonstrated with the help of XPS formation of ester bonds. The crystallinity was reduced with appearance of roughness on granules upon starch modification. Conventional dry heating method was compared with microwave heating method for preparation of 
starch maleate with durations ranging from 1 minute to 360 minutes by Xing et al. (2006). Microwave heating gave higher degree of substitution than conventional heating method, however surface indentations appeared in starch maleate products prepared using microwave heating.

Ganesh et al. (2020) compared reactions of citric acid with starch in three modes: ethanol, water as solvent and dry heat (without solvent). These authors found that anhydride formation was almost comparable in three modes, however hydrolysis was higher in dry state. Further these authors raised hypothesis that dry heat can increase kinetic energy of citric acid molecules to collide and break the glycosidic bonds of starch.

Dry heated Dioscorea starch granules in the presence of ionic gum sodium alginate showed surface roughness after the treatment. Amylose content and turbidity of starch were observed to decrease after the treatment (Flores-Silva et al., 2017). Dry heating treatment has been also observed to degrade starch and could be potential process for making dextrins (Chung et al., 2004).

Dry heating of starches proceeds with depolyermization, transglucosidation and cross linking which however may depend on starch source, crystallinity characteristics and reactions conditions (Ganesh et al., 2020). Mode of transfer of energy to molecules can alter the position of hydroxyl groups on starch molecules in favorable position to form ester bonds or for breakage of bonds. The breakage or formation of bonds may further affect crystalline structure of starch. However, more studies are needed which can explore the effects of dry heating on interactions of starch chains and the collisions between starch and reactant molecules.

\section{Irradiation}

Irradiation is increasingly used for food preservation, extending shelf life as well as to increase bioactivity of cereals. Irradiation is a cheap and environment friendly way to alter the properties of starches (Ben Bettaïeb et al., 2014). Starch irradiation is done by irradiating starch in polymeric packages and literature review suggests use of irradiation up to $10 \mathrm{kGy}$ in general. Irradiation of starch granules results in changes in chemical structure of starch such as carboxyl content, reduction in reducing sugar, amylose content, acidity, $\mathrm{pH}$ and degradation of starch molecules. It also leads to change in its functional attributes such as decrease in viscosity and increase in water solubility (Bhat and Karim, 2009). Irradiation, however, may induce negative effects on sensory and chemical properties of some foods which may depend on the absorbed irradiation dose and other process parameters. Irradiation can be used in combination with other treatments like heating or cryogenic temperature. It is also used in conjunction with modified-atmosphere or vacuum packaging for increasing shelf life of foods. However, it does not require special equipment for control of temperature or $\mathrm{pH}$ and is much simpler than other techniques (Charlesby, 1981). Irradiation process can induce changes occurring in food materials which may depend directly on the dose and rate of irradiation. Irradiation dose up to $10 \mathrm{kGy}$ used for foods is generally considered safe (Copeland et al., 2009). 
Electron beam radiation and gamma rays emitted from the radioisotopes ${ }^{60} \mathrm{Co}$ and ${ }^{137} \mathrm{Cs}$ and X-rays (Bremsstrahlung) have been used for food irradiation in many countries (Farkas, 2006). Figures 2 and 3 shows the schematic of electron beam and gamma irradiation respectively. Depending on the absorbed radiation dose, cereal grains and pulses have shown better storage and microbiological safety although loss in some vitamins and nutrients have also been reported (Basson, 2010). The operating principle of X-ray equipment consisting in converting the energy of high energy electrons into electromagnetic X-rays have advantages of adding food preservative effects without inducing radioactivity to the food materials (Farkas, 2006).

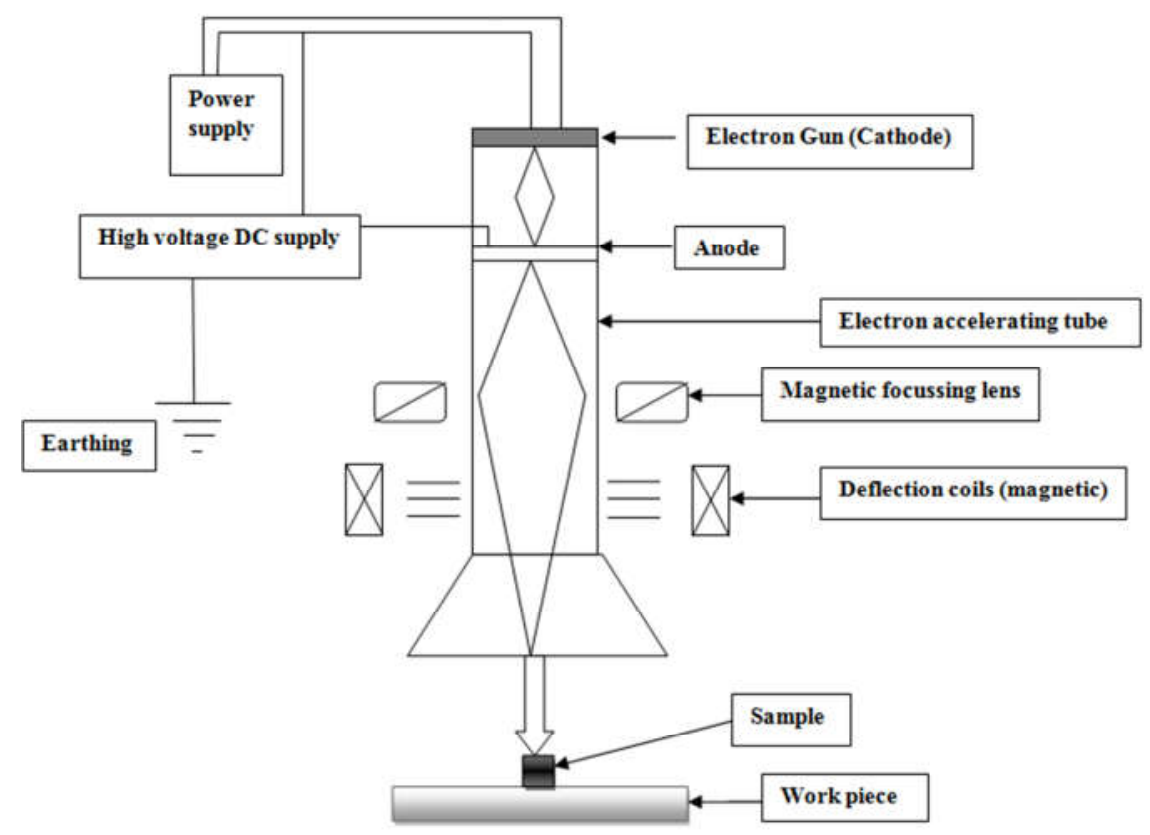

Figure 2. Schematic representation of electron beam irradiation on food sample (Adapted from Hong et al., 2008).

Table 2 indicates summary of work of gamma irradiation on starch from various sources.

Electron beam (EB) irradiation is an economical and rapid method for increasing food quality, shelf life and safety however it may depend on the irradiation dose. Electron beam radiation presents advantages over gamma radiation as it can be controlled by switch operation and the irradiation range can be changed by changing acceleration voltage (Zhai et al., 2002). The use of electron beam irradiation for achieving target functionalities in starch is time saving, economical and green in nature generating no waste (Nemțanu and Brasoveanu, 2010). EB 
irradiation can be classified as high energy $(>300 \mathrm{keV})$ or low energy electron beams $(<300 \mathrm{keV})$ which depends on kinetic energy of the electrons. The penetration of radiation unto foods depends on surface density of food materials (Zhai et al., 2003).

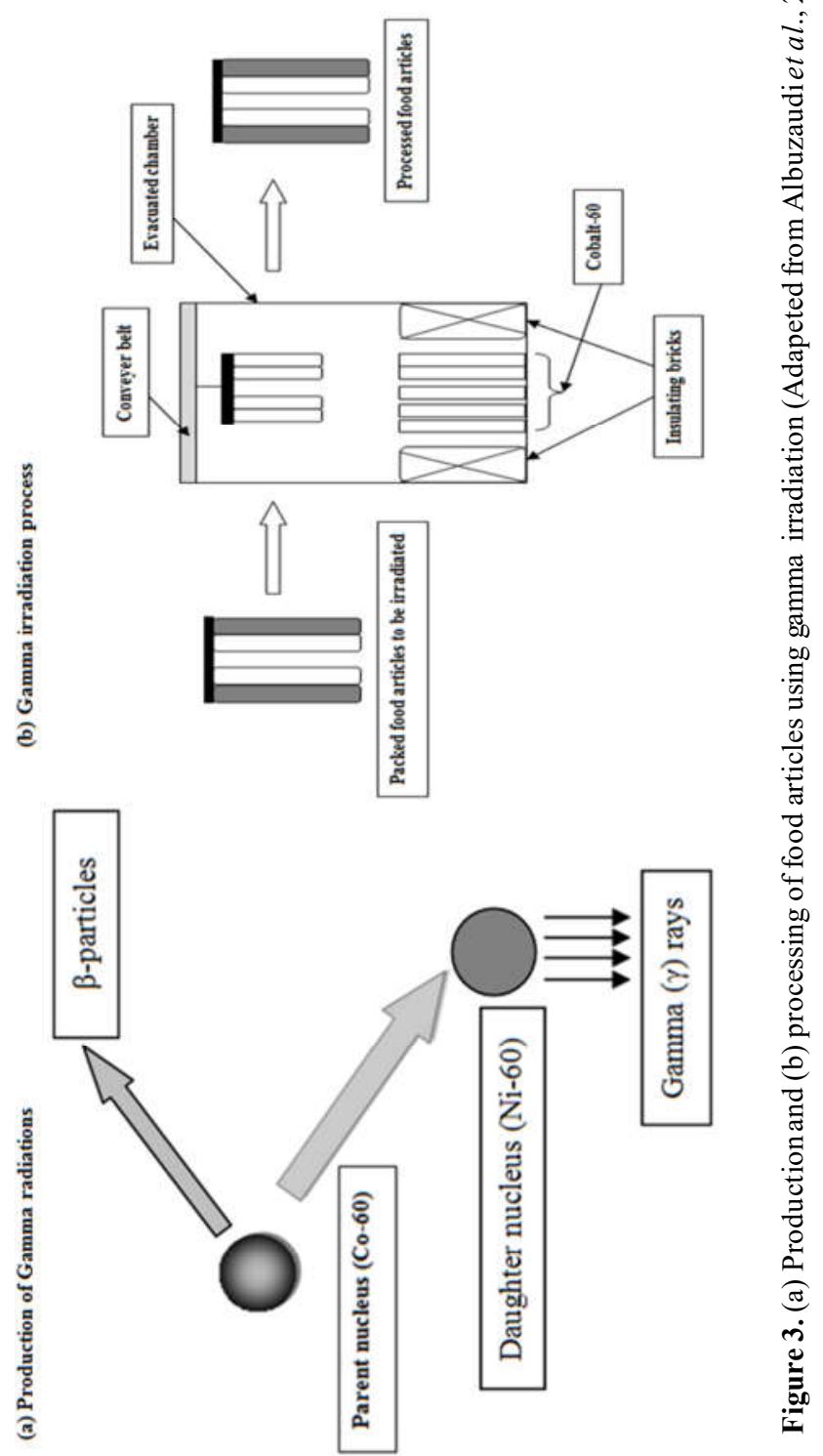


Table 2. Influence of gamma irradiation intensity on starch characteristics of various cereals.

\begin{tabular}{|c|c|c|c|}
\hline Starch Type & $\begin{array}{l}\text { Gamma } \\
\text { Radiation } \\
\text { Intensity } \\
\end{array}$ & \begin{tabular}{lllr} 
Effect & on & \multicolumn{2}{c}{ physicochemical } \\
properties & of & starches & after \\
irradiation & & & \\
\end{tabular} & References \\
\hline Rice & $\begin{array}{l}0,2 \text { and } 10 \\
\mathrm{kGy}\end{array}$ & $\begin{array}{l}\text { Increase in solubility and carboxyl } \\
\text { content but decrease in pasting } \\
\text { properties }\end{array}$ & Gul et al., 2016 \\
\hline $\begin{array}{l}\text { Cassava and } \\
\text { Waxy Maize } \\
\text { for preparation } \\
\text { of starch } \\
\text { nanoparticles }\end{array}$ & 20 kGy & $\begin{array}{l}\text { Starch nanoparticles of } 30 \mathrm{~nm} \text { were } \\
\text { obtained }\end{array}$ & $\begin{array}{l}\text { Lamanna et al., } \\
2013\end{array}$ \\
\hline Dry bean & 2.5-20 kGy & $\begin{array}{l}\text { Damage was observed on the surface of } \\
\text { granules }\end{array}$ & $\begin{array}{l}\text { Rayas-Duarte and } \\
\text { Rupnow, } 1993\end{array}$ \\
\hline Maize & $1-500 \mathrm{kGy}$ & $\begin{array}{l}\text { Degree of crystallinity was decreased } \\
\text { while polymorph pattern was unaffected, } \\
\text { the granule surface had little visible } \\
\text { change up to } 500 \mathrm{kGy}\end{array}$ & Liu et al., 2012 \\
\hline
\end{tabular}

Gamma irradiation (5, 8 and $10 \mathrm{kGy})$ caused damage of small sized granules in rice starch, however there was production of small granules also (Yu and Wang, 2007). Decrease in gelatinization temperatures of corn starch were observed with increase in dose of gamma irradiation by (Ben Bettaïeb et al., 2014). These authors attributed structural damage and weakening of starch granules to hold water for the decrease in gelatinization temperatures. Another reason could be the defects created in crystalline polymorph or change in ratio of amylopectin short chains on irradiation. Irradiation may also cause reduction in double helices leading to decrease in enthalpy to form starch gels. Nemțanu and Brașoveanu (2010) reported decrease in paste viscosity of corn starch after irradiation with electron beam of dose ranging between 10-50 kGy. The electron beam irradiation of starches isolated from maize, wheat, potato and sago was observed to cause an increment in solubility with concomitant decrease in swelling power, pasting characteristics, and molecular weight (Kamal et al., 2007; Nemțanu and Brașoveanu, 2010; Nemţanu et al., 2007). Yu and Wang, (2007) also reported decrease in peak viscosity of rice starch after gamma irradiation. A combination of X-ray and electron beam irradiation (10-100 kGy) was used for irradiating corn and potato starch by De Kerf et al. (2001). Increase in solubility of starches with concomitant decrease in swelling power were observed with increase in dose. Corn starch was irradiated by Nemţanu et al. (2007) with electron beams (4.85-52 kGy). Peak viscosity of starch was observed to decrease after irradiation with an increase in paste transmittance. Starch was degraded after irradiation. Potato starch granules shape and size were reported to remain intact even after treatment with EB radiation at higher levels of 110-440 kGy (Bhat and Karim, 2009). Figure 4 shows pasting curve of native and electron beam treated sorghum starches. Peak viscosity of sorghum starch after electron beam treatment ( $5 \mathrm{kGy})$ was observed to be similar to that of native starch however all other parameters namely breakdown viscosity, setback viscosity and 
final viscosity decreased. This indicated that electron beam can increase granular strength and decreasing retrogradation tendency. This may due to cross links formed due to electron beam irradiation. In general, due to production of free radicals on starch irradiation breakage of bonds occur which lead to lower paste viscosities.

Starch and plastic (PVA) in gel state were irradiated by electron beam to prepare the composite films by Abd El-Mohdy (2007). The films prepared showed increased swelling and gel fraction content with increase in irradiation dose and was attributed to cross-linking of films.

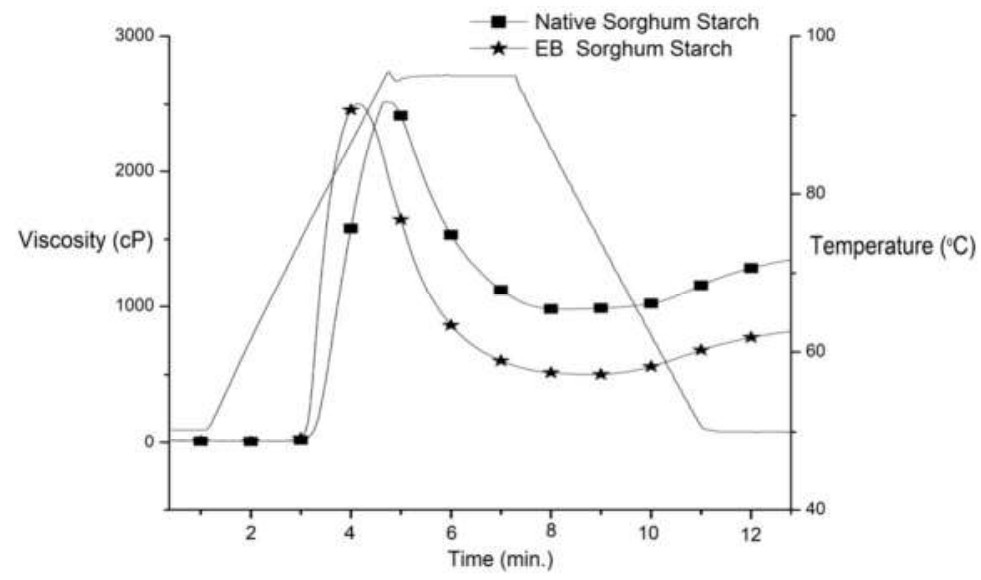

Figure 4. Pasting curve of native and electron beam ( $5 \mathrm{kGy})$ treated sorghum starches

Gel strength and solubility of sago starch increased after irradiation with electron beam in range between 10-15 kGy (Pimpa et al., 2007). Molecular weight of sago starch was also observed to decrease with increase in EB radiation which indicated towards starch degradation and production of short chains of amylose and amylopectin (Pimpa et al., 2007). Pits and cranies appeared on wheat starch granules after electron beam irradiation with $4.4 \mathrm{kGy}$ which was hypothesized to free radical generation by $\mathrm{Hu}$ et al. (2011). However, these authors did not do any analysis of free radical measurement. Molar mass and pasting viscosities of wheat starch was observed to decrease after increase in irradiation dose.

In contrast potato starch granular morphology remained intact even after doses of 110-440 kGy of EB irradiation, however X-ray diffraction intensities decreased drastically (Bhat and Karim, 2009). Some authors have reported no change in starch diffraction pattern or relative crystallinity on irradiation (Ben Bettaïeb et al., 2014). This was attributed to the limiting effect of radiation on starch chains or branch points/double helices in amorphous regions. Microscopic images of electron beam irradiation of sorghum starch at 5 and $10 \mathrm{kGy}$ are presented in Figure 5 and indicates that starch granule morphology remained unaffected by electron beam intensity change. 
There was no change in color of starch granules in our study however, Nemțanu et al. (2007) reported yellowing of starch granules on electron beam irradiation with doses up to $52 \mathrm{KGy}$. This was attributed to structural changes on irradiation. Electron beam irradiation also results in addition of carboxyl groups into starch molecules. Efficiency of starch grafting reaction with acrylamide has been observed to increase after polymerization in presence of $10 \mathrm{MeV}$ electron beam irradiation (Zhang et al., 2014). The radical formation and combination rate was increased after irradiation. The superabsorbent starch prepared by this way showed better water absorption properties. Electron beam irradiation significantly improved the interfacial adhesion between polylactic acid (PLA) and starch in the presence of glycidyl methacrylate (GMA) (Shin and Han, 2013).
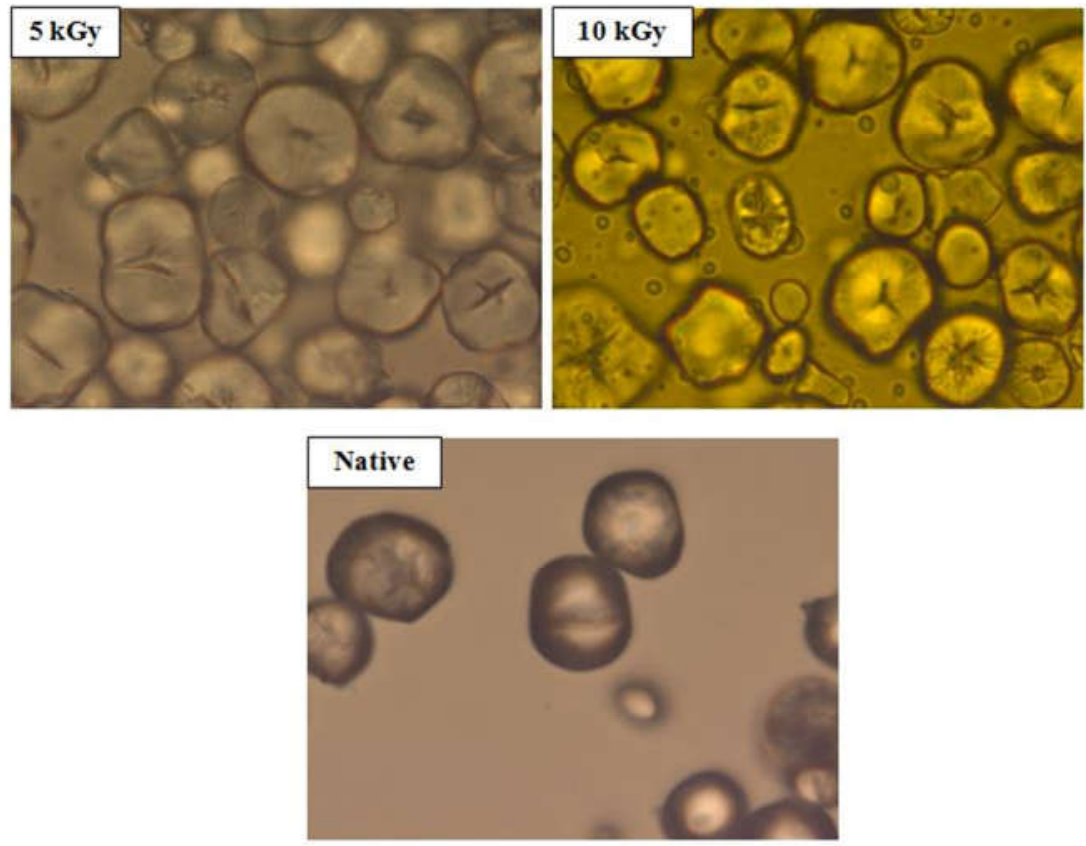

Figure 5. Microscopic images of irradiated starch samples under different doses

Irradiation is safe and environmental friendly technique to alter starch properties which depend on dose, starch source and crystalline polymorph type. Combination of electron beam, X-ray or microwave can be used to tweak properties of starch gels and application in novel food products. The irradiation can be also used to produce biodegradable hydrogel by crosslinking carboxymethyl starch (Bhat and Karim, 2009).

\section{Conclusions}

Dry heating, gamma and electron beam irradiation can replace the harsh chemical modification of starch and flours. However, these have not become much popular 
in the industry. There is a need of more technological development to integrate these technologies in the starch and flour industries. There is increased awareness on safety of food irradiation because of great number of public debates. It is accepted that there would be increase in use of irradiation in food processing and safety operations in South Asia countries where there is large scale production of cereals but poor storage facilities. The major limitation lies in the economic use of irradiation for small scale cereal batches. However, dry heating can be used at very small scales to large scales. It is accepted that major needs of food industry with respect to addition of emulsifiers, texturizing agents can be met by dry heated and irradiated starches.

\section{Acknowledgements}

The authors are thankful to TEQIP-III grant provided by MNNIT and funding by Ministry of Food Processing Industries for the partial implementation of the present research work.

\section{Conflict of Interest}

The authors have no conflict of interest of any kind with regard to this manuscript.

\section{References}

Abd El-Mohdy, H. L. 2007. Synthesis of starch-based plastic films by electron beam irradiation. Journal of Applied Polymer Science, 104, 504-513.

Arocas, A., Sanz, T., Fiszman, S. M. 2009. Improving effect of xanthan and locust bean gums on the freeze-thaw stability of white sauces made with different native starches. Food Hydrocolloids, 23, 2478-2484.

Bao, J., Shen, Y., Jin, L. 2007. Determination of thermal and retrogradation properties of rice starch using near-infrared spectroscopy. Journal of Cereal Science, 46, 75-81.

Basson, R. A. 2010. The radiation chemistry of the hydroxyl group. In Patai Chemistry of the Functional Groups: Chemistry of the Hydroxil Group, John Wiley \& Sons Ltd.

Ben Bettaïeb, N., Jerbi, M. T., Ghorbel, D. 2014. Gamma radiation influences pasting, thermal and structural properties of corn starch. Radiation Physics and Chemistry, 103, $1-8$

Bhat, R., Karim, A. A. 2009. Impact of radiation processing on starch. Comprehensive Reviews in Food Science and Food Safety, 8, 44-58.

Campo-Deaño, L., Tovar, C. A., Jesús Pombo, M., Teresa Solas, M., Javier Borderías, A. 2009. Rheological study of giant squid surimi (Dosidicus gigas) made by two methods with different cryoprotectants added. Journal of Food Engineering, 94, $26-33$.

Charlesby, A. 1981. Field enhanced luminescence of irradiated organics due to electron tunnelling. Radiation Physics and Chemistry, 17, 399-411.

Chiu C.W., Schiermeyer E., Thomas D.J., Shah M.B., 1998. U.S. Patent, 72(5), 56-76.

Chung, H. J., Liu, Q. 2010. Molecular structure and physicochemical properties of potato and bean starches as affected by gamma-irradiation. International Journal of Biological Macromolecules, 47, 214-222. 
Chung, H. J., Liu, Q., Hoover, R., Warkentin, T. D., Vandenberg, B. 2008. In vitro starch digestibility, expected glycemic index, and thermal and pasting properties of flours from pea, lentil and chickpea cultivars. Food Chemistry, 111, 316-321.

Chung, H. J., Woo, K. S., Lim, S. T. 2004. Glass transition and enthalpy relaxation of cross-linked corn starches. Carbohydrate Polymers, 55, 9-15.

Copeland, L., Blazek, J., Salman, H., Tang, M. C. 2009. Form and functionality of starch. Food Hydrocolloids, 23, 1527-1534.

Darlington, H. F., Tecsi, L., Harris, N., Griggs, D. L., Cantrell, I. C., Shewry, P. R. 2000. Starch granule associated proteins in barley and wheat. Journal of Cereal Science, 32, 21-29.

De Kerf, M., Mondelaers, W., Lahorte, P., Vervaet, C., Remon, J. P. 2001. Characterisation and disintegration properties of irradiated starch. International Journal of Pharmaceutics, 221, 69-76.

Englyst, H. N., Kingman, S. M., Cummings, J. H. 2010. Classification and measurement of nutritionally important starch fractions. Journal of Food Science, 46, 33-50.

Fallis, A. 2013. Starch chemistry and technology. Journal of Chemical Information and Modeling, 27, 31-35.

Farkas, J. 2006. Irradiation for better foods. Trends in Food Science and Technology, 17, 148-152.

Flores-Silva, P. C., Roldan-Cruz, C. A., Chavez-Esquivel, G., Vernon-Carter, E. J., BelloPerez, L. A., Alvarez-Ramirez, J. 2017. In vitro digestibility of ultrasound-treated corn starch. Starch/Staerke, 69, 3-9.

Food and Agriculture Organization of the United Nations. 2010. An international consultation on integrated crop-livestock systems for development: the Way Forward for Sustainable Production. FAO. https://doi.org/10.1016/S0272-8842(99)00101-7

Fu, Z. Q., Wang, L. J., Li, D., Zhou, Y. G., Adhikari, B. 2013. The effect of partial gelatinization of corn starch on its retrogradation. Carbohydrate Polymers, 97, 512-517.

Ganesh, A., Singh, B., Duttagupta, A., Kalita, D., Zhong, Y., Blennow, A., Singh, H. (2020). Preparation of starch citrates using solvent free reaction and comparison with aqueous and ethanol mediated reactions. Starch - Stärke, 72, 1900260.

Gonzalez-Tomás, L., Coll-Marqués, J., Costell, E. 2008. Viscoelasticity of inulin-starchbased dairy systems. Influence of inulin average chain length. Food Hydrocolloids, 22, 1372-1380.

Gul, K., Singh, A. K., Sonkawade, R. G. 2016. Physicochemical, thermal and pasting characteristics of gamma irradiated rice starches. International Journal of Biological Macromolecules, 85, 460-466.

Han, X. Z., Hamaker, B. R. 2001. Amylopectin fine structure and rice starch paste breakdown. Journal of Cereal Science, 34, 279-284.

Hong, Y. H., Park, J. Y., Park, J. H., Chung, M. S., Kwon, K. S., Chung, K., Song, K. Bin. 2008. Inactivation of Enterobacter sakazakii, Bacillus cereus, and Salmonella typhimurium in powdered weaning food by electron-beam irradiation. Radiation Physics and Chemistry, 77, 1097-1100.

Hoover, R., Hughes, T., Chung, H. J., Liu, Q. 2010. Composition, molecular structure, properties, and modification of pulse starches: A review. Food Research International, 43, 399-413. 
Hu, B., Huang, M., Yin, S., Zi, M., Wen, Q. 2011. Effects of electron-beam irradiation on physicochemical properties of starches separated from stored wheat. Starch/Staerke, 63, 121-127.

Hu, G., Chen, J., Gao, J. 2009. Preparation and characteristics of oxidized potato starch films. Carbohydrate Polymers, 76, 291-298.

Huang, J., Schols, H. A., Jin, Z., Sulmann, E., Voragen, A. G. J. 2007. Pasting properties and (chemical) fine structure of acetylated yellow pea starch is affected by acetylation reagent type and granule size. Carbohydrate Polymers, 68, 397-408.

Jenkins, P. J., Donald, A. M. 1995. The influence of amylose on starch granule structure. International Journal of Biological Macromolecules, 17, 315-321.

Katyal, M., Singh, N., Chopra, N., Kaur, A. 2019. Hard, medium-hard and extraordinarily soft wheat varieties: Comparison and relationship between various starch properties. International Journal of Biological Macromolecules, 123, 1143-1149.

Kim, J. H., Kim, H. R., Choi, S. J., Park, C. S., Moon, T. W. 2016. Production of an in vitro low-digestible starch via hydrothermal treatment of amylosucrase-modified normal and waxy rice starches and its structural properties. Journal of Agricultural and Food Chemistry, 64, 5045-5052.

Lamanna, M., Morales, N. J., Garcia, N. L., Goyanes, S. 2013. Development and characterization of starch nanoparticles by gamma radiation: Potential application as starch matrix filler. Carbohydrate Polymers, 97, 90-97.

Lehmann, U., Robin, F. 2007. Slowly digestible starch - its structure and health implications: a review. Trends in Food Science and Technology, 18, 346-355.

Lele, V. V., Kumari, S., Niju, H. 2018. Syntheses, Characterization and Applications of graft copolymers of sago starch - A review. Starch/Staerke, 70, 7-8.

Li, M., Dhital, S., Wei, Y. 2017. Multilevel structure of wheat starch and its relationship to noodle eating qualities. Comprehensive Reviews in Food Science and Food Safety, 16, 1042-1055.

Liu, T., Ma, Y., Xue, S., Shi, J. 2012. Modifications of structure and physicochemical properties of maize starch by $\gamma$-irradiation treatments. LWT - Food Science and Technology, 46, 56-163.

Marefati, A., Rayner, M., Timgren, A., Dejmek, P., Sjöö, M. 2013. Freezing and freezedrying of Pickering emulsions stabilized by starch granules. Colloids and Surfaces A: Physicochemical and Engineering Aspects, 436, 512-520.

Miao, M., Jiang, H., Jiang, B., Zhang, T., Cui, S. W., Jin, Z. 2014. Phytonutrients for controlling starch digestion: Evaluation of grape skin extract. Food Chemistry, 145, 205-211.

Morrison, W. R. 1988. Lipids in cereal starches: A review. Journal of Cereal Science, 8, 115.

Mua, J. P., Jackson, D. S. 1997. Fine structure of corn amylose and amylopectin fractions with various molecular weights. Journal of Agricultural and Food Chemistry, 45, 38403847.

Kamal, M., S. M., Mahmud, S. N., Hussain, S. A., Ahmadun, F. R. 2007. Improvement on sago flour processing. International Journal of Engineering and Technology, 4, 8-14.

Nemțanu, M. R., Brașoveanu, M. 2010. Aspects regarding the rheological behavior of the wheat starch treated with accelerated electron beam. Romanian Reports of Physics, 55, 
111-117.

Nemţanu, M. R., Minea, R., Kahraman, K., Koksel, H., Ng, P. K. W., Popescu, M. I., Mitru, E. 2007. Electron beam technology for modifying the functional properties of maize starch. Nuclear Instruments and Methods in Physics Research, Section A: Accelerators, Spectrometers, Detectors and Associated Equipment, 580, 795-798.

Noda, T., Ichinose, Y., Takigawa, S., Matsuura-Endo, C., Abe, H., Saito, K., Amauchi, H. Y. 2003. The pasting properties of flour and starch in wheat grain damaged by alphaamylase. Food Science and Technology Research, 9, 387-391.

Parker, R., Ring, S. G. 2001. Aspects of the physical chemistry of starch. Journal of Cereal Science, 34, 1-17.

Pimpa, B., Muhammad, S. K. S., Hassan, M. A., Ghazali, Z., Hashim, K., Kanjanasopa, D. 2007. Effect of electron beam irradiation on physicochemical properties of sago starch. Songklanakarin Journal of Science and Technology, 29, 759-768.

Rayas-Duarte, P., Rupnow, J. H. 1993. Gamma-Irradiation affects some physical properties of dry bean (Phaseolus vulgaris) starch. Journal of Food Science, 58, 389-394.

Shin, B. Y., and Han, D. H. 2013. Compatibilization of PLA/starch composite with electron beam irradiation in the presence of a reactive compatibilizer. Advanced Composite Materials, 22, 411-423.

Singh, H., Chang, Y. H., Lin, J. H., Singh, N., Singh, N. 2011. Influence of heat-moisture treatment and annealing on functional properties of sorghum starch. Food Research International, 44, 2949-2954.

Singh, H., Lin, J. H., Huang, W. H., Chang, Y. H. 2012. Influence of amylopectin structure on rheological and retrogradation properties of waxy rice starches. Journal of Cereal Science, 56, 367-373.

Singh, H., Sodhi, N. S., Singh, N. 2010. Characterisation of starches separated from sorghum cultivars grown in India. Food Chemistry, 119, 95-100.

Singh, H., Thakur, S., Mukhrjee, J., Nayak, T., Kumar, S., Kaur, B. 2017. Influence of acid hydrolysis on physico-chemical, structural, and pasting properties of moth bean (Vigna aconitifolia) starch. Starch/Staerke, 69, 1-28.

Singh, J., Kaur, L., McCarthy, O. J. 2007. Factors influencing the physico-chemical, morphological, thermal and rheological properties of some chemically modified starches for food applications-A review. Food Hydrocolloids, 21, 1-22.

Singh, N., Kaur, L. 2004. Morphological, thermal, rheological and retrogradation properties of potato starch fractions varying in granule size. Journal of the Science of Food and Agriculture, 84, 1241-1252.

Smith, A. M. 2001. The biosynthesis of starch granules. Biomacromolecules, 2, 335-341.

Srichuwong, S., Jane, J.-L. 2007. Physicochemical properties of starch affected by molecular composition and struictures: A review. Food Science and Biotechnology, 16, 663-674.

Sun, Y., Wu, Z., Hu, B., Wang, W., Ye, H., Sun, Y., Zeng, X. 2014. A new method for determining the relative crystallinity of chickpea starch by Fourier-transform infrared spectroscopy. Carbohydrate Polymers, 108, 153-158.

Surendra Babu, A., Parimalavalli, R., Rudra, S. G. 2015. Effect of citric acid concentration and hydrolysis time on physicochemical properties of sweet starches. International Journal of Biological Macromolecules, 80, 557-565. 
Tester, R. F., Morrison, W. R. 1994. Properties of damaged starch granules. V. Composition and swelling of fractions of wheat starch in water at various temperatures. Journal of Cereal Science, 20, 175-181.

Tester, Richard F., Karkalas, J., Qi, X. 2004. Starch - Composition, fine structure and architecture. Journal of Cereal Science, 39, 151-165.

Tian, Y., Li, Y., Xu, X., Jin, Z. 2011. Starch retrogradation studied by thermogravimetric analysis (TGA). Carbohydrate Polymers, 84, 1165-1168.

Vamadevan, V., Bertoft, E. 2015. Structure-function relationships of starch components. Starch/Staerke, 67, 55-68.

Waigh, T. A., Gidley, M. J., Komanshek, B. U., Donald, A. M. 2000. The phase transformations in starch during gelatinisation: A liquid crystalline approach. Carbohydrate Research, 328, 165-176.

Wang, S., Li, C., Copeland, L., Niu, Q., Wang, S. 2015. Starch Retrogradation: A Comprehensive Review. Comprehensive Reviews in Food Science and Food Safety, 14, 568-585.

Won, S. Y., Choi, W. S., Lim, H. S., Cho, K. Y., Lim, S. T. 2000. Viscoelasticity of cowpea starch gels. Cereal Chemistry, 77, 309-314.

Wu, Y., Chen, Z., Li, X., Wang, Z. 2010. Retrogradation properties of high amylose rice flour and rice starch by physical modification. LWT - Food Science and Technology, 43, 493-497.

Wurzburg, O. B. 1986. Modified starches: Properties and uses. Boca Raton, FL: CRC Press, United States.

Xing, G.-X., Zhang, S.-F., Ju, B.-Z. Yang, J.-Z. 2006. Microwave-assisted synthesis of starch maleate by dry method. Starch/Stärke, 58, 464-467.

Yu, Y., Wang, J. 2007. Effect of $\gamma$-ray irradiation on starch granule structure and physicochemical properties of rice. Food Research International, 40, 297-303.

Zhai, M., Yoshii, F., Kume, T. 2003. Radiation modification of starch-based plastic sheets. Carbohydrate Polymers, 52, 311-317.

Zhai, M., Yoshii, F., Kume, T., Hashim, K. 2002. Syntheses of PVA/starch grafted hydrogels by irradiation. Carbohydrate Polymers, 50, 295-303.

Zhang, S., Wang, W., Wang, H., Qi, W., Yue, L., Ye, Q. 2014. Synthesis and characterisation of starch grafted superabsorbent via $10 \mathrm{MeV}$ electron-beam irradiation. Carbohydrate Polymers, 101, 798-803.

Zuo, Y., Gu, J., Yang, L., Qiao, Z., Tan, H., Zhang, Y. 2013. Synthesis and characterization of maleic anhydride esterified corn starch by dry method. International Journal of Biological Macromolecules, 62, 241-247. 